\title{
A large indoor tidal mud-flat ecosystem
}

\author{
P. A. W. J. DE Wilde \& B. R. Kuipers \\ Netherlands Institute for Sea Research; Texel, The Netherlands
}

\begin{abstract}
This paper presents a technical description and some preliminary results of a relatively large experimental tidal mud-flat ecosystem, constructed in parallel set-ups in the experimental aquarium of the Nederlands Instituut voor Onderzoek der Zee (NIOZ). The system was build in 1975, filled with sea-water and natural sediment from a typical Arenicola marina habitat. After introducing micro-phytobenthos and juvenile $A$. marina, the development in both systems, without correcting interventions, were followed for about two years. Studies on nutrient concentrations and organic matter, primary productivity, fluctuations in biomass, density of secondary producers and activity of micro-organisms reveal the systems to be selfpertaining and fairly stable. The study of assemblages of hardy inhabitants of the stressful intertidal environment seems to be a promising starting point for further micro-system research.
\end{abstract}

\section{INTRODUCTION}

Though a large amount of relevant data from various disciplines about the tidal flat areas of the Dutch Wadden Sea have been collected, we are still far from understanding this ecosystem. Detailed information is scarce on such basic topics as the amount, dispersion and ultimate deposition of allochtoneous organic matter from the North Sea (which considerably subsidizes the system); the part detritus plays in the food chains; the activities of micro-organisms; the importance of the meiofauna, etc. Fluctuation in primary production and in biomass and productivity of animal populations, mainly due to annual changes in weather conditions, are also largely unexplained. Modeling such a complex as a tidal flat ecosystem is at present far from possible. Therefore, as a first step, the mud flats were brought within an experimental sphere, where we hoped it would be possible to achieve a workable model of a simple laboratory-scaled, tidal flat system under controlled conditions.

For various reasons, laboratory-scaled systems are still little explored ecological tools (Taub, 1974). The apparent simplicity of the so-called "balanced aquarium" seems to be a myth. Up to now the life span of self-maintaining laboratory systems without regulating intervention has shown itself to be short: only a few weeks to six months. Experimental tidal mud flats and their specialized inhabitants that adapt to extremely varying environmental conditions, inherent to their habitat, probably offer distinct advantages over other aquatic systems. The experimental NIOZ-aquarium at Texel (de Blok, 1975) offered excellent opportunities to realize the construction of 
two multi-species tidal mud-flat ecosystems (Fig. 1). A selected assemblage of microphyto benthos and polychaete worms was thought to offer the best start. During a descriptive period, starting in June 1975, input, biomass and output of the interacting parts of the simplified food chain were studied.

\section{CONSTRUCTION AND OPERATION}

\section{Equipment}

The scheme given in Figure 2 shows the general set-up of one of the two identical indoor ecosystems, constructed in the NIOZ experimental aquarium (de Blok, 1975).

The central basin (1), which contains the mud flat proper is shown in detail in Figure 3. This concrete basin (1), measuring $10.0 \times 2.5 \times 1.0 \mathrm{~m}$ is divided by a $0.4 \mathrm{~m}$ bar (2), into two compartments. The smaller part (3), with a surface of $5 \mathrm{~m}^{2}$, represents the tidal channel; the larger part (4), with a surface of $20 \mathrm{~m}^{2}$, contains the tidal flat.

The lower basin (5) has a subterranean water storage of $60 \mathrm{~m}^{3}$, from which water is circulated continuously through the upper level basin (6). From here the basin (1) is provided with sea-water, entering the channel by the inlet tube (7). The water leaves the basin (1) through the outflow tube (8) which leads directly from the channel back to storage (5).

In special cases, when the interstitial water also needs to be removed, the outflow tube can be connected with a cistern at the bottom of the mud flat. The cistern consists of a layer of porous drainage pipes (9), covered with a layer of nylon wool (10), which prevents mud from entering the cistern.

Above the mud flat, illumination panels (11) are mounted at adjustable heights. Two ventilators (12) blow constantly over the mud flats. The water circulation is controlled automatically by a number of time switches, which are connected to magnetic valves in tubes (7) and (8), and to the level sensors in the communicating gauge tubes (13) outside the channel. The time switches also regulate the light cycle. Only recently temperature control of the inflowing water became possible by mounting a graphite heat exchanger in tube (7). Heat is extracted from the sea-water by a 15 h.p. cooling system.

\section{Sediment}

The $30-40 \mathrm{~cm}$ thick sediment layer in the flat compartment was derived in April 1974 from the neighbouring Mok Bay, where the sediment was taken from an area with a dense lugworm population as deep as the Hydrobialayer (van Straaten, 1952). Sterilizing that bulk of $16 \mathrm{~m}^{3}$ of sediment was unfeasible so instead the sediment was first immersed in fresh water for several weeks, after which it was dried in the open air. When the fully mixed sediment was introduced into the system, there was, with the exception of some algae, no sign of higher forms of life. The grain size distribution of the sediment is given in Table 1 . 

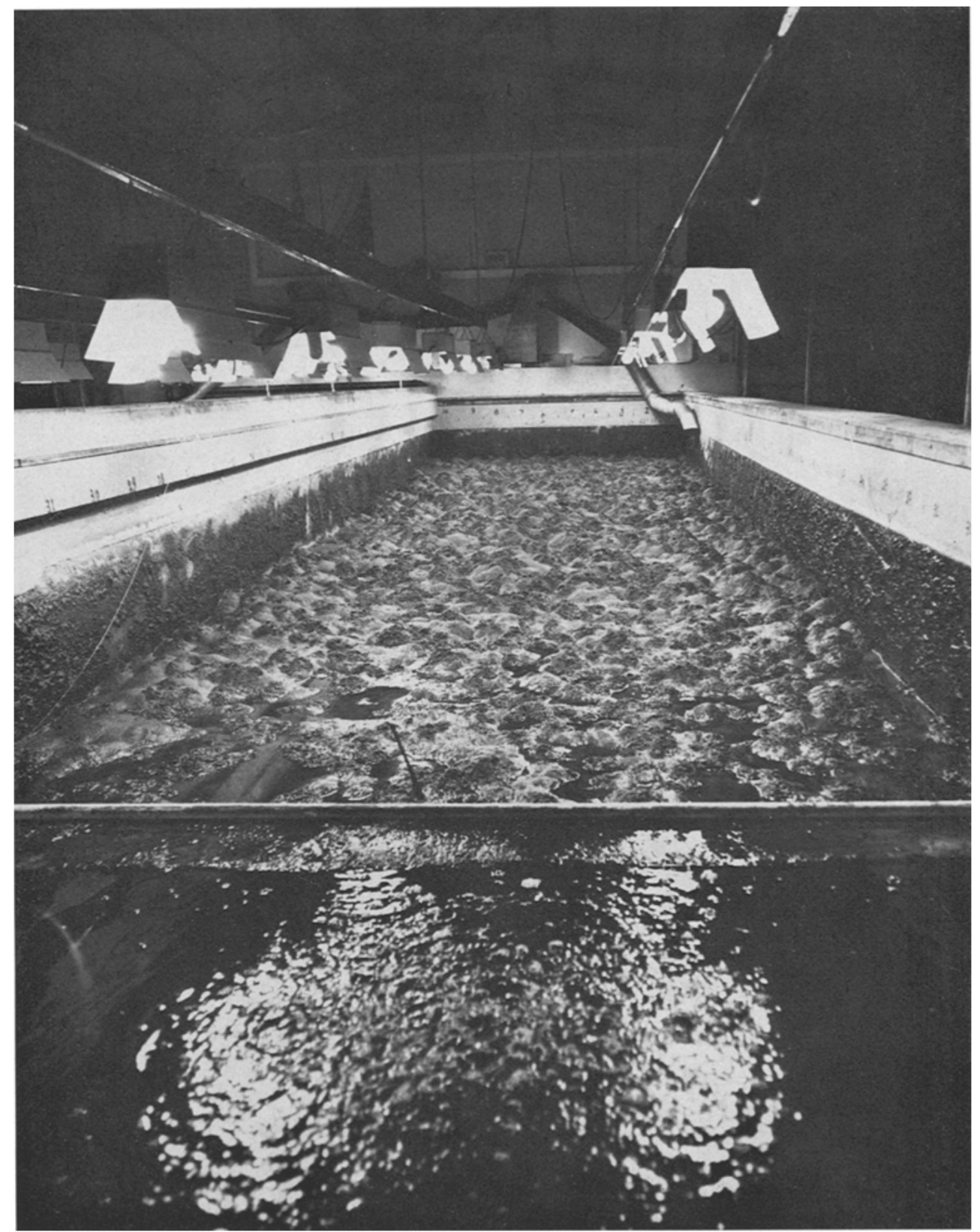

Fig. 1: The indoor tidal ecosystem during low water with the 'tidal-channel' in the foreground and the mud flat covered with the casts of Arenicola marina in the background 


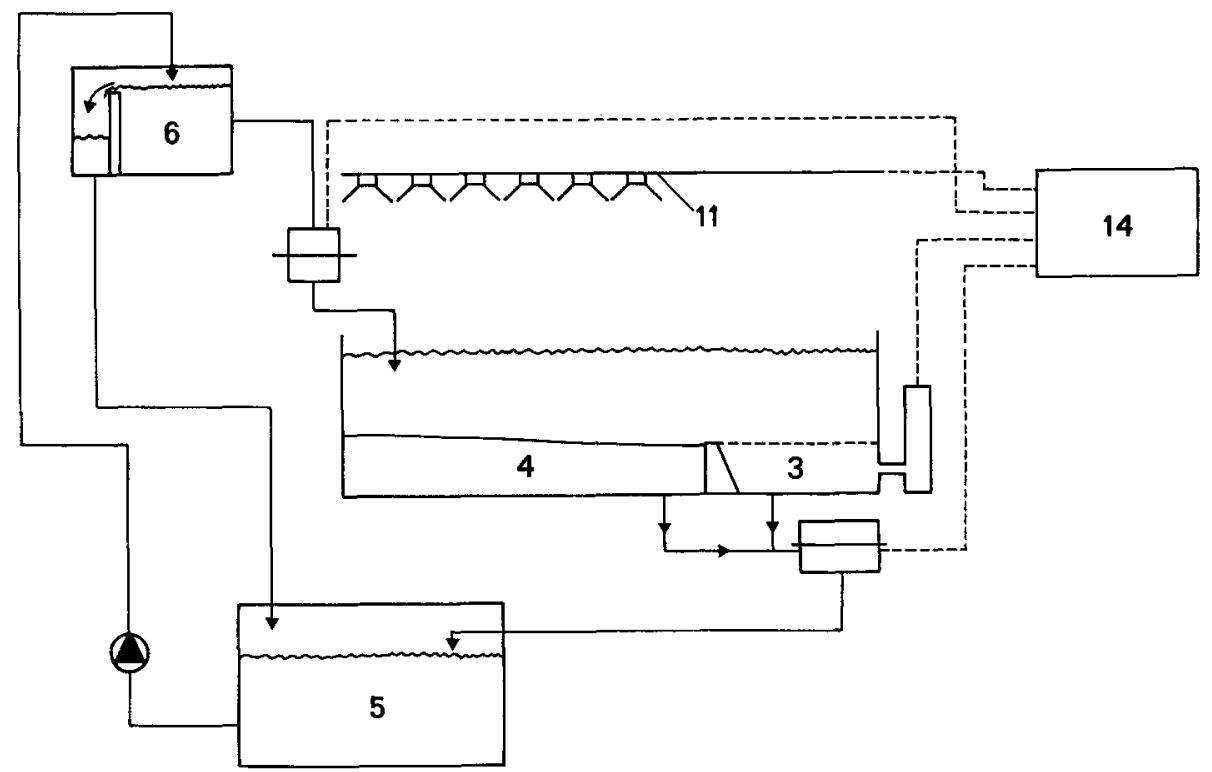

Fig. 2: Diagram showing the water circulation and illumination controlled by electrical switches (for explanation see Fig. 3)

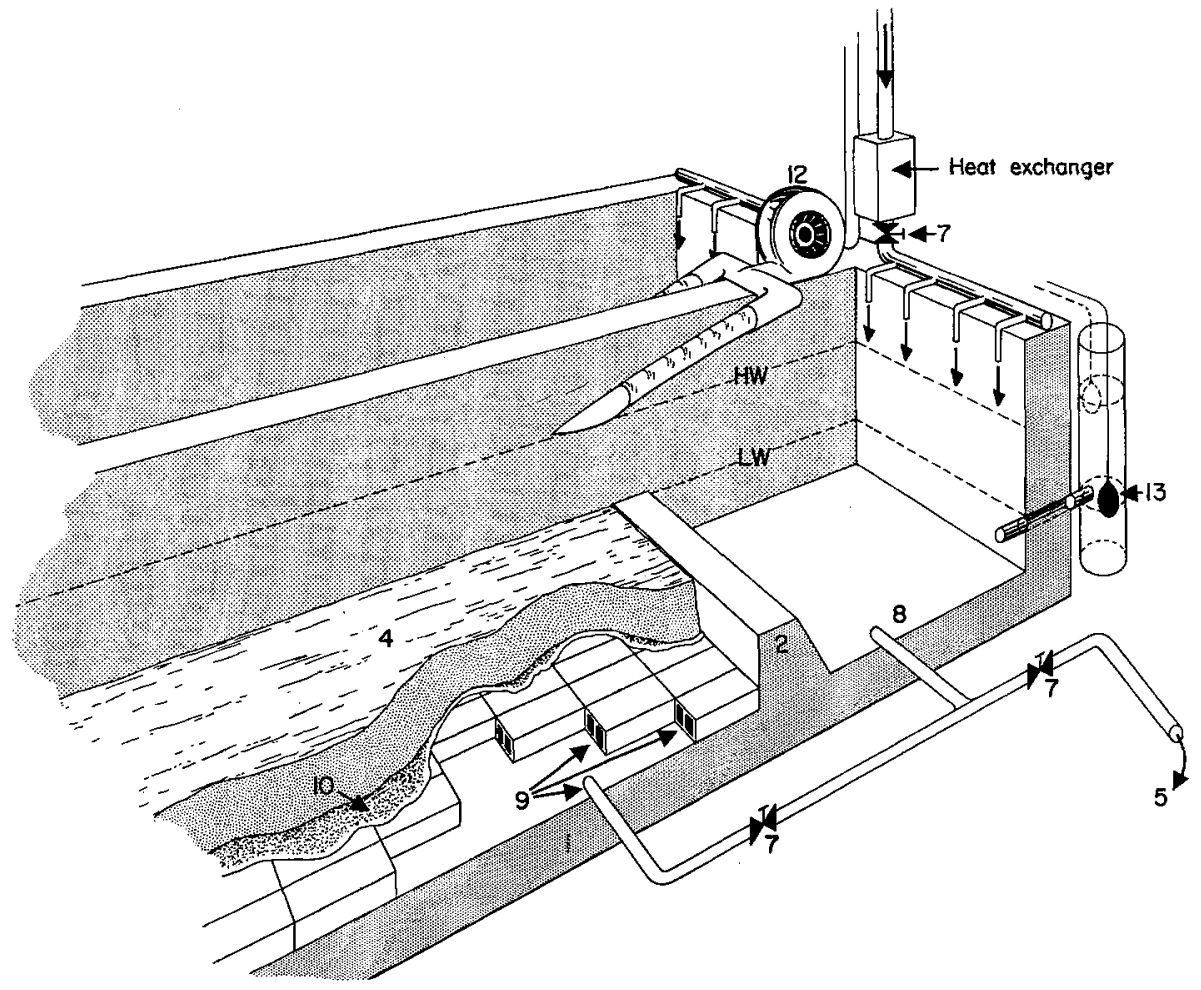

Fig. 3: Schematic drawing of the tidal mud-flat basin, showing: 1 concrete basin, 2 bar, 3 tidal channel, 4 mud-flat, 5 storage basin, 6 level tank, 7 magnetic valves, 8 drain, 9 cistern, 10 nylon wool layer, 11 lamps, 12 ventilators, 13 level-gauge containing censors, 14 time switches 
Table 1

Mean percentages $(\%)$ and standard deviations (s) of grainsize fractions in $\mu$ ( $\mathrm{f} \mu$ indicating lower limits of fraction) of the original sediment. (After Baumfalk, 1977)

\begin{tabular}{|rrr|}
\hline $\mathrm{f}_{\mu}$ & \% & $\mathrm{s}$ \\
\hline 0 & 3.12 & 0.4927 \\
50 & 1.65 & 0.2576 \\
100 & 6.70 & 0.7399 \\
160 & 32.63 & 0.9598 \\
200 & 33.46 & 1.0744 \\
250 & 16.11 & 0.8249 \\
315 & 5.25 & 0.3544 \\
400 & 1.04 & 0.4467 \\
\hline
\end{tabular}

The percentage of organic matter in the sediment determined by combustion and by Colemann carbon analysis was rather high $(\approx 2 \%)$. Shortly after the start of the experiment the complete sediment, except for the upper $1 \mathrm{~cm}$ layer turned black and anaerobic. E.T.S.-measurements showed a natural mineralisation profile (Vosjan \& Olanczuk-Neyman, 1977).

\section{Water}

The systems water was taken from the Marsdiep, the main tidal inlet near the island of Texel in winter 1974. It was held in quarantine for several months in order to remove lutum, all kinds of larvae and small organisms and the majority of planctonic algae before it was put in the storage tanks. The water was not filtered. The initial salinity of $25 \%$ was kept constant by regularly adding fresh water from a local plant. This did not change the nutrient concentration significantly. On an average 5001 of fresh water per month were added per $60 \mathrm{~m}^{3}$.

In each system, ventilators produce a slow horizontal circulation in the water masses and moreover generate ripples on its surface during the period of high water. Due to this action the water stays clear of floating particles and the depositing matter is distributed equally over the flat. Although the water is not filtered during its return, pelagic organisms and suspended matter are almost absent in the storage tank.

Sedimentation on the bottom of the tank is negligible and the walls of the tank stay clear.

\section{Light}

Day light is completely excluded. The system attains its light energy by high pressure sodium vapour discharge lamps, Philips SON/T, $400 \mathrm{~W}$. At present there are 12 lamps above each mud flat, $1.25 \mathrm{~m}$ above its surface and operating in a sequence of $12 \mathrm{~h}$ light: $12 \mathrm{~h}$ dark. The energy level amounts to about $90 \mathrm{~W} / \mathrm{m}^{2}$. This type of lamp was chosen because of its block-shaped relative spectral light distribution, the major part of which is in between 550 and $620 \mathrm{~nm}$, which is within the sensitive range 
of the chlorophyll. Moreover, the yield of effective energy for photosynthesis is large $(>25 \%)$ as compared to heat production.

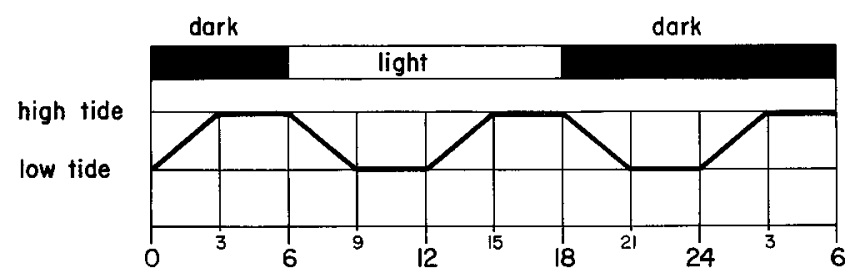

Fig. 4 : The $12 \mathrm{~h}$ tidal and $24 \mathrm{~h}$ light cycle of the experimental system

\section{Tidal and light cycle}

Figure 4 shows the tides in the basin and also the light cycle, together resulting in a strict $24 \mathrm{~h}$ periodicity. Although the technical facilities are present the complicated natural shifts in day-length, light intensity and times of high water were for reasons of simplicity not yet simulated.

\section{Temperature}

In spring 1975 a study was made of the daily temperature variations and the heat balance in one of the two systems. In order to do so the double amount of light irradiance, $180 \pm 20 \mathrm{~W} / \mathrm{m}^{2}$ was used and a daily shifting tide with a period of $12.5 \mathrm{~h}$. Becht (1976) constructed a numerical model, predicting temperature variations that agreed very well with variations actually measured. The daily and annual temperature fluctuations in the indoor system are mainly absorbed by the large subterranean storage of water. The daily variation in temperature in the upper sediment layers amounts to $4-5^{\circ} \mathrm{C}$. The annual temperature variation lies within the range of 12 and $23^{\circ} \mathrm{C}$. Temperature controlling equipment became available recently and was tested at this time.

\section{Nutrients}

During the descriptive period monthly measurements of nutrient concentrations and organic matter were done in the water as well as in the interstitium at several depths. Table 2 summarizes the concentrations of $\mathrm{PO}_{4}, \mathrm{NO}_{3}, \mathrm{NO}_{2}, \mathrm{NH}_{3}$ and $\mathrm{SiO}_{4}$ of the overlying water at the start of the experiment.

\section{Oxygen}

In general the oxygen saturation level of the water, including the water in the storage basins is near $100 \%$. However, large fluctuations in saturation may occur in 
the thin water film just over the sediment. Here, due to organisms/sediment respiration and stratification, saturation may drop to values of $40 \%$ or below. In small tidal pools even total absence of $\mathrm{O}_{2}$ has been recorded during the night. On the other hand, during the light period oversaturation of $200 \%$ and more, obviously related to photosynthesis, has been observed. The combination of tidal rhythms together with those of day and night cause complicated patterns of high and low oxygen saturation in the benthic boundary layer.

\section{Experimental organisms}

A natural mixture of benthic algae scraped from the tidal flats of the Balgzand, was put into settling-tubes, then unwanted sediment particles and organisms (Hydrobia) were removed as possible, and the remainer spread over the sediment. Within 2 or 3 weeks the mud flat was overgrown with a yellow-brown diatom cover.

In late June/early July, 1975, each of the two systems was equally stocked with 4000 juvenile lugworms (Arenicola marina). These worms, also collected in the Mok Bay all descended from the previous spawning season, November 1974. They were spread evenly over the surface. At the time of introduction their mean body length was $11.1 \mathrm{~mm}$ (tail end not included); the mean ash free dry weight was $5 \mathrm{mg}$. As will be seen later, erroneously some juvenile specimen of Nereis diversicolor must have been introduced too.

\section{DEVELOPMENTS IN THE SYSTEM}

Since June, 1975 the tidal mud-flat ecosystem was left without any correcting interventions for nearly two years, during which several parameters were followed. Temperature, albedo, salinity, $\mathrm{pH}$, oxygen saturation were registrated continuously. Although the results will be published separately by the respective co-workers, some general remarks are made here.

$\mathrm{Nutri}$ ents. During the first three months nutrient concentrations in the water increased rapidly, obviously caused by mineralisation of organic matter in the sediment. The increased bioturbation by the fast growing lugworms will have facilitated both the mineralisation itself as well as the release of nutrients from the interstitium. During the preceding six months nutrient concentrations showed a gradual decline towards more or less stable levels (Table 2). The relatively low concentrations of nitrite and ammonia point to the healthy condition of the systems. Concentration profiles of nutrients in the sediment, invariably point out the state of continuous unrest in this part of the system. This is also ascribed to the high rate of bioturbation.

Primary production. In agreement with the rather low input of light energy, productivity measurements $\left(\mathrm{C}_{14}\right.$ method) showed in general a moderate, more or less stable fixation of carbon amounting to about $0.1 \mathrm{~g} / \mathrm{m}^{2} /$ day. For a period of 4 months, in one of the two mud flats an extraordinary high production of 1-2 g C/ $\mathrm{m}^{2} /$ day was measured. 
During the two-year period of observation the relatively high initial amount of organic matter in the sediment $(\approx 2 \%)$ did not change significantly, not by the share of primary production, nor by the decrease caused by consumption of secundary producers or by mineralisation.

Table 2

Initial concentrations of $\mathrm{N}$-compounds, phosphate and silicate measured on 23.6. 1975 in the overlying water of the two tidal mud-flat ecosystems. Maximum values were found after 3 months in the northern basin (Column 2). Column 3 gives the stabilized levels in the same basin after 6 months. The development of nutrient concentrations in the other basin was 1-2 months retarded, but occurred in a similar way

\begin{tabular}{|c|c|c|c|c|}
\hline \multicolumn{2}{|c|}{ Nutrients ( $\mu$ gat $/ 1)$} & \multicolumn{3}{|c|}{$\begin{array}{c}\text { Concentrations } \\
\text { after } 3\end{array}$} \\
\hline Ammonia & $\left(\mathrm{NH}_{4}{ }^{+}\right)$ & 1 & 70 & 10 \\
\hline Nitrite & $\left(\mathrm{NO}_{2}^{-}\right)$ & $0.15-0.5$ & 4.5 & 1.0 \\
\hline Nitrate & $\left(\mathrm{NO}_{3}\right)$ & 63 & 115 & 40 \\
\hline Phosphate & $\left(\mathrm{PO}_{4}^{3^{3-}}\right)$ & 4 & 63 & 60 \\
\hline Silicate & $\left(\mathrm{H}_{4} \mathrm{SiO}_{4}\right)$ & 5 & 360 & 200 \\
\hline
\end{tabular}

$\mathrm{Me}$ i of a u n a. Meiofauna was sampled only during the first year. It consisted mainly of small nematodes and harpacticides; species diversity being low with 6 species of nematodes as compared to some 40 in the natural situation. Total biomass of meiofauna was low, hardly exceeding values of 1-2 $\mathrm{g}$ ash free dry weight, which is only $3 \%$ of the biomass of the macrofauna.

$\mathrm{Ma}$ c r of a u na. Due to initial high mortality, the lugworm population in each system decreased from 4.000 to about 3.000 specimens during the first weeks. Afterwards only sampling caused a slight but constant decline in the populations. After one year the number of the lugworms amounted to some 1.700 in each tank. Densities of 85 per $\mathrm{m}^{2}$ are not extremely high when compared to the natural situation.

The numbers of Nereis individuals, investigated in one of the two tanks, fluctuated strongly with densities in the range of some 100 up to 7.500 per $\mathrm{m}^{2}$. The total biomass of both macro-organisms together, was in the order of $50 \mathrm{~g}$ ash free dry weight per $\mathrm{m}^{2}$, of which Nereis accounted for one fifth. Within one year Arenicola marina reached an average body length (without tail) of about $80 \mathrm{~mm}$ and an ash free dry weight of $430 \mathrm{mg}$. During their first year $A$. marina reached sexual maturity, one year earlier than comparable lugworms in the wadden sea. Spawning was observed in autumn 1975 and 1976. Fertilized eggs were then abundant. Several months later, however, juveniles were only present in a few places where the adult worms were scarce. Nereis diversicolor proved to spawn abundantly in the indoor systems. Waves of juveniles appeared on the mud surface several times a year. Secundary producers will have subtracted a considerable amount of organic matter from the sediment. Since the carbon percentages of the sediment stayed approximately constant, the input by photosynthesis was thought to sustain the system. 


\section{APPLICABILITY OF THE PRESENT SYSTEM IN FUTURE RESEARCH}

After two years of observation an overall conclusion may be, that this system shows various predictable trends and tends to reach a certain steady state. The system contains a collection of organisms, belonging to different trophic levels, composed in the laboratory in such a way that the mutual relations are coherent to those found in nature. As the term of life is now about two years and there are no indications of any significant deterioration, the system meets the most important requirements of a microsystem (Ringelberg, 1976).

The physical conditions in the wadden sea, like those in most other estuarine areas, are often stressful and species diversity correspondingly low. A selected assemblage of these hardy "wadden species", therefore, is able to stand the experimental conditions in our system over extended periods, much better than most fresh-water or marine organisms, when brought together in microsystems.

A unique feature of the present system is the heavy bioturbation, caused by the infauna, which keeps the surface of the mud flat free from higher algae. Moreover mineralisation processes are accelerated by the reworking of the sediment, which also has an increased oxygenation.

The indoor tidal flats provide many possibilities for experimental analysis of phenomena described in the field. A number of experiments, pertaining to the effects of bioturbation in the mud-flat ecosystem; a detailed study on the part detritus plays in the food web was started recently. Since bioturbation here is mainly caused by polychaetes, a detailed ecological study of these organisms will be also made.

Acknowledgements. This project was carried out by the following co-workers: W. Helder, R. T. P. de Vries (chemical analysis); C. G. Cadée, J. Hegeman (primary production); J. J. Zijlstra, J. Y. Witte (meiofauna); E. M. Berghuis, B. R. Kuipers, P. A. W. J. de Wilde (macrofauna); J. H. Vosjan (microorganisms). Technical assistance was offered by H. J. Boekel. The drawings were made by $\mathrm{H}$. Hobbelink.

\section{LITERATURE CITED}

Baumfalk, Y. A., 1977. Heterogeneous grainsize distribution produced by bioturbation activity of the European lugworm Arenicola marina L. Int. Rep. N.I.O.Z., 1-15 (mimeogr.).

Becht, H. Y., 1977. De warmtehuishouding van een waddengebied. Int. Rep. N.I.O.Z., 1-120 (mimeogr.).

Blok, J. W. de, 1975. The Texel aquarium. Neth. J. Sea Res. 9, 231-242.

Ringelberg, J., 1976. The possibilities of a new kind of micro-ecosystem in the aquatic ecosystem research. Hydrobiol. Bull. 10, 17-18.

Straaten, L. M. J. U. van, 1952. Biogene textures and the formation of shell beds in the Dutch Wadden Sea. Proc. K. Ned. Akad. Wet. (B) 55, 500-516.

Taub, F. B., 1974. Closed ecological systems. R. A. Rev. Ecol. Syst. 5, 139-160.

Vosjan, J. H. \& Olanczuk-Neyman, K. M., 1977. Vertical distribution of mineralization. Neth. J. Sea Res. 11, 14-23.

First author's address: P. A. W. J. de Wilde

Netherlands Institute for Sea Research

Texel

The Netherlands 